\title{
Exploring the Use of Genre Analysis for EFL Speakers ${ }^{1}$
}

\section{(Exploración del uso del análisis de los géneros discursivos para los hablantes del inglés como idioma extranjero)}

Sherry E. Gapper ${ }^{2}$

Universidad Nacional, Costa Rica

\begin{abstract}
RESUMEN
El presente estudio examina las ventajas y desventajas del análisis de los géneros discursivos para el procesamiento de textos auténticos como guía para quienes hablan inglés como idioma extranjero o traducen a esa lengua. Los géneros discursivos se entienden en un sentido amplio como categorías textuales. Hay numerosas investigaciones recientes sobre asuntos referidos a los géneros discursivos, pero en el presente caso lo que se resalta es más bien el desarrollo y la puesta en práctica de un modelo que se utiliza para encontrar y analizar un conjunto de textos auténticos de determinado género para identificar los rasgos distintivos de ese género, con el fin de contar con una guía durante la redacción o traducción de textos en la lengua no materna.
\end{abstract}

\begin{abstract}
This study addresses the advantages and disadvantages of genre analysis for the processing of authentic texts to serve as a guide for EFL learners, speakers and translators when writing in English or translating into that language. For the purposes of this paper, genres are understood in a broad sense as textual categories. Much work has been done in recent years in different areas of genre research, but here the emphasis is on the development

1 Recibido: 19 de agosto de 2013; aceptado: 30 de setiembre de 2013. Elaborado con base en la ponencia presentada por la autora en el IV Congreso Internacional de Lingüística Aplicada, llevado a cabo en mayo de 2013, en el Campus Omar Dengo, de la Universidad Nacional de Costa Rica.

2 Escuela de Literatura y Ciencias del Lenguaje. Correo electrónico: sgapper@hotmail.com
\end{abstract}


of a simplified, practical (classroom-tested) model which may be used to locate and analyze a set of sample (authentic) texts of a given genre in order to identify the distinguishing features of that particular textual genre for their use as a guide in various EFL production tasks.

Palabras clave: inglés como lengua extranjera, traducción, género discursivo Keywords: English as a Foreign Language (EFL), translation, genre

\section{Introduction}

Nothing perhaps is more frustrating than to spend time and effort writing or translating a text into a non-native language, just to discover that although it may be grammatically or lexically error-free, it is still inappropriate, and does not comply with what native speakers expect of that type of text. The main objective of this study is to address the advantages and disadvantages of genre analysis for processing authentic texts to serve as a guide for EFL learners, speakers and translators while writing in English or translating into that language. Much work has been done in recent years in different areas of genre research, ${ }^{3}$ or on teaching a critical analysis of genres, ${ }^{4}$ for example. However, in our study the emphasis is on the development of a simplified, practical (classroom-tested ${ }^{5}$ ) model which may be used to locate and analyze a set of sample (authentic) texts of a given genre in order to identify the distinguishing features of that particular textual genre for their use as a guide in various EFL written production tasks. The approach described here is not simply that of a certain type

3 A useful overview may be found in: Anis S. Bawarshi and Mary Jo Reiff, Genre: An Introduction to History, Theory, Research, and Pedagogy (Bolder, CO: The WAC Clearinghouse: 2010).

4 Amy Devitt, "Teaching Critical Genre Awareness," Charles Bazerman et al., Genre in a Changing World (West Lafayette, IN: Parlor Press, 2009) 337-351.

5 This paper is one of the results of an ongoing study carried out over the past ten years, in which the participants have not been made aware that their results were being recorded, or indeed, that a specific treatment was being applied. This has been done to eliminate the risk of bias due to their awareness of participating in an experiment. In the study reported on here, groups of 20 to 30 students were provided information and given assignments over a semester-long period to determine the effectiveness of the model. The results were then used as a basis for further refinement of the model and its implementation. 
of genre analysis; it is, above all, a way to foster a greater awareness of genre and sensitivity to the presence of distinctive stylistic or syntactic features in any specific textual genre, so that they may then be used appropriately when writing or when translating.

Whenever use is made of the word "genre," it is wise to clarify in what sense it is being used. For our purposes, a broad definition such as that proposed by Silvia Gamero-Pérez, which views a genre as a sort of prototype where all texts possessing similar characteristics are grouped, makes it possible to include text-types that otherwise would have been excluded. ${ }^{6}$ Gamero-Pérez considers that this is a comprehensive, but flexible definition that covers many different related aspects excluded by others and emphasizes not only the conventional linguistic characteristics of a text, but also the communicative situation itself.

Even native speakers of a language are often at a loss when asked to write a document using a text-type that they have never read and much less written. Similarly, when translating such a document into their mother tongue, people tend to use inappropriate language unless they are already familiar with the conventions of that type of text. It should not, therefore, be surprising that non-native speakers of English, or of any language, experience even greater difficulties. There is a need then for a way to translate (or write) correctly and appropriately in one's non-native language, even when using genres with which one is not familiar. Native speakers of a language can benefit from this possibility as well. The type of genre analysis proposed here responds to the need for an awareness of style and an ability to recognize the features characterizing one genre or another; it also leads to an increasing sensitivity to how the language is used.

6 Silvia Gamero-Pérez, La traducción de textos técnicos (Barcelona: Ariel, 2001) 49-51. GameroPérez includes, for example, in her analysis the importance of the seminal work done in this sense by J. M. Swales, Genre Analysis. English in academic and Research Settings (Cambridge: Cambridge University Press, 1990). 
One existing approach is to provide the learner with a series of characteristics that must be applied when writing or translating within a particular genre, as occurs with the different genres covered in Medical Translation Step by Step, ${ }^{7}$ which refers to very specific syntactic and lexical characteristics of patient information leaflets and of other different types of medical texts. That can be very useful for a certain genre and can be quickly and successfully applied. However, students often fail to develop skills enabling them to analyze other genres by themselves in the future, because of their lack of exposure to the set of texts from which this information was extracted. Furthermore, it is clear that teaching students to write wellorganized essays, as is often done in composition courses, does not enable students to write or translate, for instance, lab reports, business letters or executive summaries. Each genre has its own form of organization and linguistic features.

The approach discussed below can be described as a process in which the student is encouraged to both learn and acquire the ability to use authentic texts as guides for the appropriate use of the language within a particular genre. Information will be provided on the analysis procedure and on its implementation with a group of students.

\section{Analysis Procedure}

What then is required is a way to approach any genre with which the translator has not had previous (or sufficient) experience in one or both languages, either as a language user or as a translator. That procedure may be summarized briefly as seen in Figure 1.

7 Vincent Montalt-Resurrecció and María González Davies, Medical Translation Step by Step (Manchester, UK: St. Jerome, 2007). 
Identification of the genre(s) and

subgenre(s) of the text to be translated

Search for samples of the genre(s) and subgenre(s) in the source text language and in the target language

Explicit (and subconscious) identification of distinctive stylistic, syntactic and lexical features in texts in each language

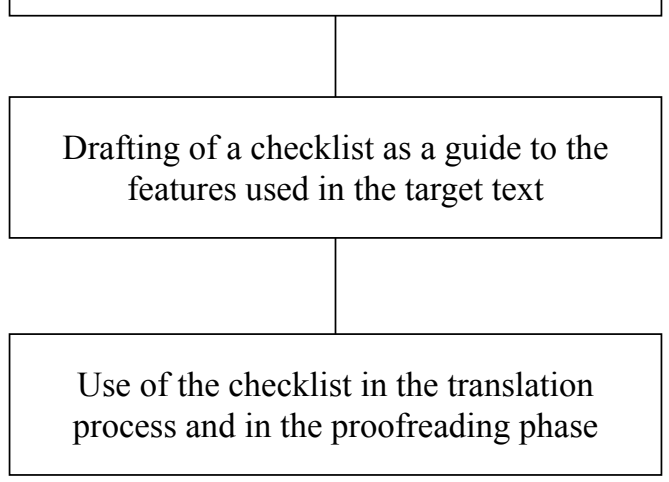

Figure 1. Different phases of the process

Once the genre has been identified, the instructor or the students must locate sufficient samples of that genre in both languages. The actual quantity or length of texts required may vary according to the specific case. There should be enough to ensure that the samples are, in fact, representative of the particular genre. In highly structured genres, a few samples may suffice because it rapidly becomes apparent that certain linguistic features are present in every text. Above all, the texts chosen must be reliable, and selected from authoritative sources for 
the respective type of text. It goes without saying that the texts selected must correspond to the genre in question, and they must be authentic texts, written originally in the target language. While a translated text may occasionally shed light on the translation process itself, it is not as reliable because interference may have been introduced while translating. This interference from the source language can affect the frequency of specific structures (verb tenses, parts of speech, and word order, among others), which varies from one language to another, or it may cause unusual idiomatic expressions to be introduced.

Further information will be given below about each of the above phases as the implementation of the model is discussed. In time, if the process is repeated once and again, it will be carried out on an increasingly subconscious level to the point that eventually either it will no longer be necessary, or the user will no longer be aware of even doing it. With experience, the "checklist" as such, mentioned above, may no longer be required. In any case, a checklist can only be representative of many more aspects associated in turn with each of the items on the list; therefore, once the notions are acquired, much more detail can be actually be covered.

\section{Implementation of the Process}

The process itself consists of at least seven related aspects which must be taken into consideration as it is being implemented with a group of students. These aspects include - but are by no means limited to - the following: 1) an overview of concept of genre itself; 2) an overview of the significant features of a genre; 3) an introduction to initial examples (cookbooks, business letters) with features that are easily identified; 4) guidelines for the selection of texts; 5) the introduction of examples of increasing similarity and complexity; 6) an introduction of cases of subgenres of a similar type; and 7) an introduction of cases of subgenres within a particular type of text. These aspects provide the background or framework 
needed for the sample genres to be taken better advantage of, and will be outlined below.

\section{Overview of the concept of genre}

Students must clearly understand the relatively informal concept of genre (article, report, memo, letter, etc.), as it is used here, and realize that it encompasses more than the literary genres which they may already be familiar with. It must it not be confused with that of field (biology, economics, medicine), in spite of the fact that each field also can and should be characterized linguistically. This concept may be difficult for some at first. In addition, students may find it hard to differentiate between one genre and another, or initially, to identify what distinguishes them. They commonly report that they see nothing outstanding in one text or another. They say that the texts look "normal." Often one must recur to very different genres (recipes vs. poems; or lab report vs. email memo) to start directing people's attention toward distinguishing features. Once this point has been reached, students may find it useful to refer to an initial list of possible types of linguistic features to identify.

\section{Overview of significant features}

In the initial stages, it is important to emphasize that there is a set of specific linguistic features that tend to characterize and define each genre. This can be exemplified by considering a familiar genre such as that of instruction manuals, and an easily identifiable structure such as the imperative. It can then be observed that instruction manuals written originally in Spanish tend to have a different percentage of imperatives if compared to those written originally in English. With this basis, more information may be offered regarding the types of syntactic and lexical characteristics which often distinguish one type of text from another. A list of linguistic features such 
as that of Biber and Conrad, ${ }^{8}$ can add further detail for this purpose. Comparative information on the use of certain structures (such as that of García-Yebra ${ }^{9}$ ) may also be provided as another form of support.

It is essential for the students themselves to discover some of the features so that they will develop the ability to continue discovering additional features in new types of text that they will have to work with in the future. However, in the meantime, it speeds the learning process if they are given an initial list of features that are apt to vary between one genre and another, or between one language and another. At the same time, they may be asked to take note of other characteristics that they may discover as well. Some of the linguistic features mentioned above may be of use for this purpose.

\section{Introduction to initial examples}

The use of initial examples taken from genres which vary from one language to another, and which have also varied over the course of time in each language is another simple way to stimulate the growth of the students' capacity to perceive these differences. For instance, the case of recipes may be presented: recipes written 300 years ago in Spanish, recipes written 300 years ago in English, current recipes in Spanish and current recipes in English. Another very illustrative case is that of business letters. This introduces the idea of developing an awareness of usage patterns and tendencies.

\section{Guidelines for the selection of texts}

At the present time, the Internet has greatly facilitated locating appropriate texts for these purposes. Translators no longer have to go to libraries and institutions to find the information that they require. Students are familiar with search engines such as that of Google, but must be oriented regarding the selection of the particular texts.

8 Douglas Biber and Susan Conrad, Register, Genre, and Style (Cambridge: Cambridge University Press, 2009) 78-82.

9 Valentín García-Yebra, Teoría y práctica de la traducción (Madrid: Gredos, 1984). 
As indicated above, the texts must have been written originally in the target language, and come from reliable sources. Students may be provided initially with URLs, or with specific search techniques that they can apply to locate texts, and they can be given guidelines for text selection. As they gain experience, they will find it easier to locate appropriate texts quickly. If translating into English, it is useful to have a small set of texts in Spanish (the source language), as well as a larger set of texts in the respective genre in the target language. The same applies when intending to write in one's non-native tongue; it is essential to become aware of the features which should not be transferred from one's native language in a given genre.

\section{Introduction of examples of increasing similarity and complexity}

As time passes and as the students become more familiar with the features that may distinguish one genre from another, texts of increasing similarity and complexity may be introduced. Consider, for example, the stylistic differences existing between academic articles in the humanities and in the natural sciences. An enhanced observation of the text-type enables EFL writers and translators to apply the appropriate features as needed. The differences may not be as evident as before, but they are perhaps of greater importance. If they are not taken into consideration, they can seriously affect readability, especially in the case of scholarly texts.

\section{Introduction of cases of subgenres of a similar type}

While it is relatively simple to identify the features distinguishing a business letter from a recipe, greater attention is required to identify the significant features of a business letter, when compared to a personal letter. As a matter of fact, they will share a number of characteristics. By noticing what is found in common in a set of business letters, and in a set of personal letters, it is possible not only to have a guide for translating either variety, but also to develop the ability to take note of differences which would have gone by unnoticed beforehand. The use of formulaic expressions is very significant in administrative documents. 


\section{Introduction of cases of subgenres within a particular type of text}

When approaching a translation, as a case in point, it is necessary to identify the genre in the source language, and take note of how the given text coincides or deviates from that genre. One must be familiar with the corresponding genre in the target language, use features appropriately when translating it, and make the respective deviations as needed. In addition, certain parts of a text of a given genre also have their very particular characteristics, such as the use of specific verb tenses, gerunds or noun-noun compounds in one section or another.

Take the case of a business letter. An overall knowledge of what is expected in a business letter in Spanish is required in order to recognize the style (old fashioned and flowery, or modern and more concise) as a basis for the translation. It is essential to recognize what elements contribute to define the style used. Then in the translation phase, one must have an overall knowledge of business letters in English as well. Knowledge of how the style has evolved through the years and of what elements form part of that style will serve as a basis for translation decisions throughout the letter. Without that knowledge, a more literal translation of that business letter would lead to a target-language version that has the effect of being more formal than it was in Spanish. It could appear to have a slightly archaic style that it did not have in Spanish. Careful observation of business letters shows that at times Spanish letters contain use phrases and grammatical structures whose literal equivalents would be considered wordy or obsolete in English.

In the case of an EFL speaker who wishes to draft a business letter in English, unless that person is already familiar with different types of business letters in English, the resulting letter will inevitably contain features commonly found in Spanish business letters which form the underlying basis. On the other hand, by becoming familiar with a number of authentic letters written originally in English in different circumstances, the EFL speaker will have the components required to draft an acceptable letter which will be clearly understood by English speakers. 


\section{Results}

All in all, it has been observed that the above procedure eventually leads not only to a more appropriate use of the language but also to a greater awareness of the effect achieved by particular syntactic and stylistic features. This contributes to the EFL users' confidence in their writing and translating, and provides a concrete basis for the decisions that they make throughout the writing process. For them to reach that goal, however, it is essential to prevent common problems which may appear during the learning process. The following areas have proven to be problematical:

Over-specificity during the selection process: At first, it is common for a student to look for a text that is exactly like the one at hand, and then be frustrated not to find one. It is not necessary, or even desirable, for the reference text to be too similar to the text to be translated, because what is sought here is an overall picture of the identifying linguistic features of a given genre.

Over-dependence on the examples found: Experience has shown, albeit surprisingly enough, that some students, rather than writing or translating a letter or a contract, might decide to select one of the sample texts and just add the new data corresponding to that case. For example, regarding the genre of business letters (which has been used above to exemplify the process) and the subgenre of consumer complaints, the student might find a letter of consumer-complaints written originally in the target language, and simply change the information describing the complaint. That option is, of course, incorrect, and could be considered a naïve form of plagiarism. For that reason, the concept of plagiarism should also be discussed at this point, to prevent misunderstandings and misuse of sample texts.

Over-generalization: It is essential to use examples to highlight the fact that just because an element is found in one of the samples, that does not mean that it is characteristic of all of them or even that it will be found in others at all. The feature identified may 
have been a peculiarity of the particular author of the text, but that in itself is valuable information for the translator, for instance, who can then proceed to create the same effect the target language.

Misuse of the features identified: Initially, it is not surprising to observe the misuse or over-use of the features identified. The instructor's role is then to provide additional guidance or explicit indications regarding the use of one structure or another. At the same time, it is important to show how guidelines for the use of any one pattern or tendency can be gleaned from a more careful analysis of the sample texts. Stylebooks may also warn against using specific words that impress beginning writers as appropriate for formal texts, but they do not include the specialized orientation required. The correct use of sample texts in a given genre can fulfill this need as well.

If precautions such as those mentioned briefly above are taken, it is possible for students or even advanced users of EFL to develop the new skills needed to analyze texts linguistically and formulate working hypotheses as to the use of the language within a certain genre. These hypotheses are then gradually verified as the task progresses. An additional goal is that of facilitating the gradual acquisition of the language of a particular genre. Before continuing, it must be recalled that the principal aim of the process described in this paper is not to provide a model for the scientific study of a genre. Models for that purpose exist, ${ }^{10}$ and numerous studies have been carried out on selected genres in both English and Spanish, such as that of Núñez-Ladevèze on journalistic texts, ${ }^{11}$ or that of Borja's work on different genres within the field of legal translation. ${ }^{12}$ Useful workbooks

10 Models of this sort may be found in Douglas Biber and Susan Conrad, Register, Genre, and Style (Cambridge: Cambridge University Press, 2009).

11 Luis Núñez Ladevèze, Métodos de redacción periodística y fundamentos de estilo (Madrid: Síntesis, 1993).

12 Anabel Borja-Albi, El texto jurídico inglés y su traducción al español (Barcelona: Ariel, 2000). 
also exist for the purpose of preparing people to use a specific genre, ${ }^{13}$ as sometimes occurs also in English for Specific Purposes (ESP)

Here the goal is to present a model which facilitates familiarization first on a conscious level and then on a subconscious level. That is, the eventual goal is for the translator to be able to skim a few texts of the genre studied, and without further conscious analysis while translating, apply the characteristic observed. Knowledge of the concepts of learning and acquisition as commonly understood in the language-learning process is useful at this point. The same phenomenon could be said to apply to the translation process itself and to the use of genre-analysis as a tool. The process analyzed above is intended first of all to foster the strategies applied when analyzing a set of texts explicitly, and then gradually to lead to the development of the ability to do the same unconsciously.

A number of advantages of this approach may be mentioned. It has been seen that this model hastens the practical application of knowledge acquired through genre analysis, and later fosters the acquisition of genre competence. It increases the users' awareness of stylistic features and thus contributes to the quality of translations into a non-native language, as well as to that of texts written originally by non-native speakers. It provides a basis for the user to write or translate acceptably within a given genre, using second-language features appropriately, and eliminating an undue influence of sourcetext features. In addition, it enables users (even native speakers) to write or translate acceptably within a genre with which they were not previously familiar.

As outlined above, possible drawbacks must be foreseen and will require specific treatment. Like any other tool or approach, it is also essential to keep in mind that this is not the only concept that

13 An example of this type is that of Robert Weissberg and Suzanne Buker, Writing Up Research: Experimental Research Report Writing for Students (Englewood Cliffs, NJ: Prentice Hall Regents, 1990), in which they refer to the syntactic and lexical characteristics of each one of the sections of a research paper. 
will serve an EFL student or a translator as a guide, and it must not be used in isolation. Contrastive approaches, and many others, have been proposed as solutions in the past and have been rejected later on because they were assumed to be the sole solution to a translation problem or for language learning. Here the genre-approach is intended to be used in combination with other strategies and with a series of other extratextual, intratextual and intertextual considerations.

From the very beginning of one's work with genres when translating, it is important to point out that one should not replace entire sections of one text with sections taken from another text. In legal texts such as contracts, for example, one must not necessarily use the format of the texts studied in the target language instead of the format of the original. However, the translator can take very good advantage of the linguistic features or formulaic expressions of these comparable texts to solve numerous translation issues. It is also clear that these sample texts may also be used for terminology purposes, but that is outside the scope of the present discussion.

\section{Conclusion}

This approach to developing genre awareness and stylistic sensitivity can be characterized as follows:

- It is a gradual process which may be hastened quite efficiently by systematic guidance.

- The comparison of very different genres, particularly in initial stages, enhances the students' ability to recognize distinguishing features.

- Partial lists of typical characteristics to watch out for are useful in the initial stages.

- $\quad$ Students must be encouraged to discover the distinctive features of a genre themselves, rather than being taught fixed sets of features for particular genres. 
- $\quad$ Practice may be provided with a variety of genres to improve the students' ability to identify the significant features. This is more worthwhile in the long term, because if students are simply trained to use one genre after another, they do not necessarily develop skills to work with unfamiliar genres which they may encounter in the future.

While it might appear that providing students with a list of features to apply would lead to better initial results, if that is done, as time passes students end up depending on pre-established lists of features rather than developing the ability to identify them whenever they come upon a type of text with which they have not worked before. The key point here is that their awareness of the syntactic, lexical and stylistic features of different genres is what enhances the quality of their work.

In addition to the usefulness of this technique for translators, it must be emphasized that it is just as useful for EFL speakers when writing in English especially in genres with which they are not already sufficiently familiar. Careful observation of grammatical and lexical features of a particular genre gives EFL speakers a basis for using those features in their own written (or oral) production, be it in translations or otherwise. It also serves as a basis from which to interpret the meaning of a text. For a native Spanish-speaker, an English letter may be misinterpreted as it could appear to be overly direct and to the point.

Although the case discussed above refers mainly to native Spanish speakers who are learning English or translating from Spanish into English, it follows that the procedure described would be just as applicable in any other language combination, and would lead not only to a more appropriate usage of the target language, but also to greater confidence in the use of that language. 